要

\title{
PRIVACY DIMENSIONS: A CASE STUDY IN THE INTERIOR ARCHITECTURE DESIGN STUDIO
}

\author{
O. Osman Demirbas and Halime Demirkan \\ Department of Interior Architecture and Environmental Design, Bilkent University 06533, \\ Bilkent, Ankara, Turkey
}

\begin{abstract}
The most commonly used space in architectural education is the studio, which functions both as a learning centre and as a complex social organization. The behavioural elements in the design studio are analysed with respect to the social processes of environmental psychology; namely privacy, personal space, territoriality and crowding. A case study was conducted to evaluate the differences between the desired and actual conditions of a design studio in the Department of Interior Architecture and Environmental Design at Bilkent University. The expectations and preferences of the interior architecture students pertaining to the design studio were analysed by considering the sex differences in patterns of privacy preferences and the results of this study are expected to be used as input for a new design studio. Results showed that there was no difference between preferences of solitude, reserve, anonymity, and isolation among sexes. Although there was a significant difference among sexes where females preferred intimacy with family and males preferred intimacy with friends.

(C) 2000 Academic Press
\end{abstract}

\section{Introduction}

The aim of this study was to carry out empirical research through a case study on privacy regulations in the design studio, which is the most widely used space in a design education institute. The privacy dimensions of the users of a design studio were measured in relation to the social processes of environmental psychology, namely, personal space, territoriality, and crowding. It was important to put forward the occupants' understanding of these concepts in order to understand their expectations relating to these behavioural elements. It was also aimed to apply the scales developed by Pedersen (1979) to investigate sex differences in patterns of privacy preferences among the students in the design studio.

\section{Design studio}

The design studio in architectural education, being similar to the other educational environments, functions both as an educational centre and a communication medium (Deasy \& Lasswell, 1985; Demirbas, 1997). Design is the most fundamental course in architectural education, in which the students gain practical and theoretical knowledge and learn to transform this knowledge with their creativity to the representation of a design model (Schön, 1984, 1987). The design students are expected to work in these areas, not only during class hours, but also in their free time (Stamps, 1994; Demirbas, 1997; Shaffer, 1999). Besides Stamps (1994) claimed that one third to one half of the educational time of a design student is spent in the design studio. Therefore, there should be a living process in the design studio.

Sanoff (1993) states the perception of an environment as supportive or hostile, interesting or boring is integral to the understanding of school environments. Learning environments can be more educationally and optimally useful if the architecture of the built, natural and cultural environment can be used as a teaching tool (Ahretzen \& Evans, 1984; Taylor, 1993; Demirkan, 1996). Galvin (1993) proposed that the main aim should be to create an environment. Besides, the physical space of the learning environment is the marker for launching creative thinking (Nelson \& Sundt, 1993). This study examines the impact of spatial characteristics of a design studio on privacy dimensions. The built 
environment elements or furniture may be the definer of a student's environment in a design studio. Students locate their drawing desks according to their own preference in a design studio. The desk may be near a wall, near a desk or near an architectural element such as a column or a corner. Also, students may group their desks with those of close friends. The territory defined by these desks may be separated by small cabinets or partitions. Some students like to bring personal belongings, such as posters or flowers, or put decorations on the walldisplays to form their own personal space. Therefore, the environmental psychology mechanisms (Gifford, 1987), privacy, personal space, territoriality, and crowding, should be analysed for the studio environment because usually these are factors which result in preferring or not preferring an environment.

\section{Privacy requirements in a design studio}

Although privacy is the condition of the individual (Chapin, 1951; Westin, 1967; Weiss, 1983; Schoeman, 1984; Gavison, 1984; Newell, 1998), the environment in which the individual exists is also related to the concept of privacy (Chermayeff \& Alexander, 1963; Hall, 1969; Canter \& Canter, 1971; Duvall-Early \& Benedict, 1992). The definition of privacy varies for each individual due to different personal characteristics, cultural backgrounds, sex, age, economical, educational and social backgrounds (Altman, 1975, 1976, 1977; Newell, 1994, 1995, 1998). In brief, privacy can be considered as the regulation of the interaction between the self and others and/or environmental stimuli (Pedersen, 1997; Kupritz, 1998; Newell, 1998). The most basic need for privacy can be stated as the optimization of social contact with both incoming and outgoing information and avoiding unwanted crowding within the environment (Altman, 1975; Kupritz, 1998).

Before now, the concept of privacy in psychology literature was considered to be one-dimensional (Pedersen, 1987). In Westin's (1967) theoretical analysis on the functions of privacy, it was suggested that there are four different kinds of privacy. These four kinds are solitude, reserve, intimacy, and anonymity. Afterwards, Marshall (1974) empirically determined Westin's four states of privacy and found two additional states: not-neighbouring, and seclusion Later, Pedersen (1979) stated six states of privacy as a result of an empirical study. In Pedersen's classification, seclusion and not-neighbouring are not considered, and instead, like Westin's classifications, he defines solitude, reserve, anonymity, and inti- macy. Differing from Westin's classification, Pedersen (1979) extended Westin's research and found isolation, which was similar to solitude but more strict, and he divided Westin's intimacy into two: intimacy with friends and intimacy with family.

Solitude is the condition of being alone and unobserved by others, and it is a condition which is either desirable or neutral. In solitude there is no need to be geographically removed from others. For Pastalan, the distinguishing characteristics of solitude were solitariness and physical isolation (Newell, 1995). In the design studio, this case study tries to find out what solitude means to a design student. It questions whether they prefer to work in their domestic environments, or to be in the studio and create an environment of their own. Reserve proposed by Westin involved the establishment of psychological barriers against intrusion (Altman, 1976). According to Pastalan, it was the most subtle form of privacy because of its reciprocal nature and the willing discretion of significant others (Newell, 1995). In a design studio, a student can keep a distance in personal relations away from his/her friends or put up some physical barrier to keep away the intrusions. Anonymity is a type of privacy that gives the individual an opportunity to move around in public without being recognized or being the subject of attention. In design education, at the end of each project a design jury takes place. Each student has to demonstrate and present his/her work for the jury and his/her classmates. In order to be successful, the student should share ideas with his/her classmates and receive criticism from the instructors. So anonymity is not a desired state for design education. Since design flourishes with interaction between individuals, isolation as a means of physical separation does not have a positive effect on the performance of the design student. Pedersen (1979) explains isolation as a state of privacy being similar to solitude, but refers to it as a physical separation of oneself from others. Intimacy is a type of privacy that is related to an individual's or group's desire to promote close personal relationships with only preferred individuals. As claimed by Newell (1995), if people do not have an opportunity for privacy, intimacy could not exist. Pedersen (1987) divided intimacy into two: intimacy with family, and intimacy with friends. Intimacy with family is the desire to be alone with family, whereas intimacy with friends is the desire to be alone with friends. Dissatisfaction within the studio environment may be the result of intimacy with family. Therefore, both kinds of intimacy may have an effect on the space chosen to conduct the design process. 


\section{Setting of the study}

The fourth year studio of the Department of Interior Architecture and Environmental Design at Bilkent University was the setting for this study. This studio is a good representative of all design studios (29 in number) at Bilkent University in terms of spatial characteristics common to all Turkish Universities. The fourth year studio was chosen because there is a serious design process taking place in it, especially during the second semester as the credits of the course increase from 6 to 9, and the design studio is expected to be the second home of the students. The studio is organized as an open-plan layout, the physical features of which give the users the opportunity to be by himself/herself in the studio and to create private corners within this space. There is the possibility of having both social interaction and avoiding social interaction in this studio, due to its physical features such as columns, and secluded corners (see Figures 1 and 2). Also, these physical elements prevent the space being a dull environment.

\section{Method}

The study was conducted using a questionnaire consisting of two different parts (see Appendix). The first part of the questionnaire consisted of multiple choice questions in which more than one answer could be given for a single question. Initially, some personal information from the occupants, such as age, sex, and accommodation type (whether they were living with their parents, living in dormitories, living alone, or with friends), was collected. Secondly, information concerning the way participants perceive the behavioural elements of space was identified. Lastly, some information about privacy regulations in the design studio was determined (see Appendix, Part I).

The second part of the questionnaire consisted of a 5-point numerical scale which measured the six states of privacy regulation as Pedersen (1979) defined (see Appendix, Part II). The six states of privacy were measured in this part, with a questionnaire similar to the studies of Pedersen (1979), and Rustemli and Kokdemir (1993) (see Table 1). Before starting the experiment, a pilot study was conducted. Consequently it was noticed that three questions were not suitable and they were omitted. In the final version there were 27 questions covering the six different states of privacy.

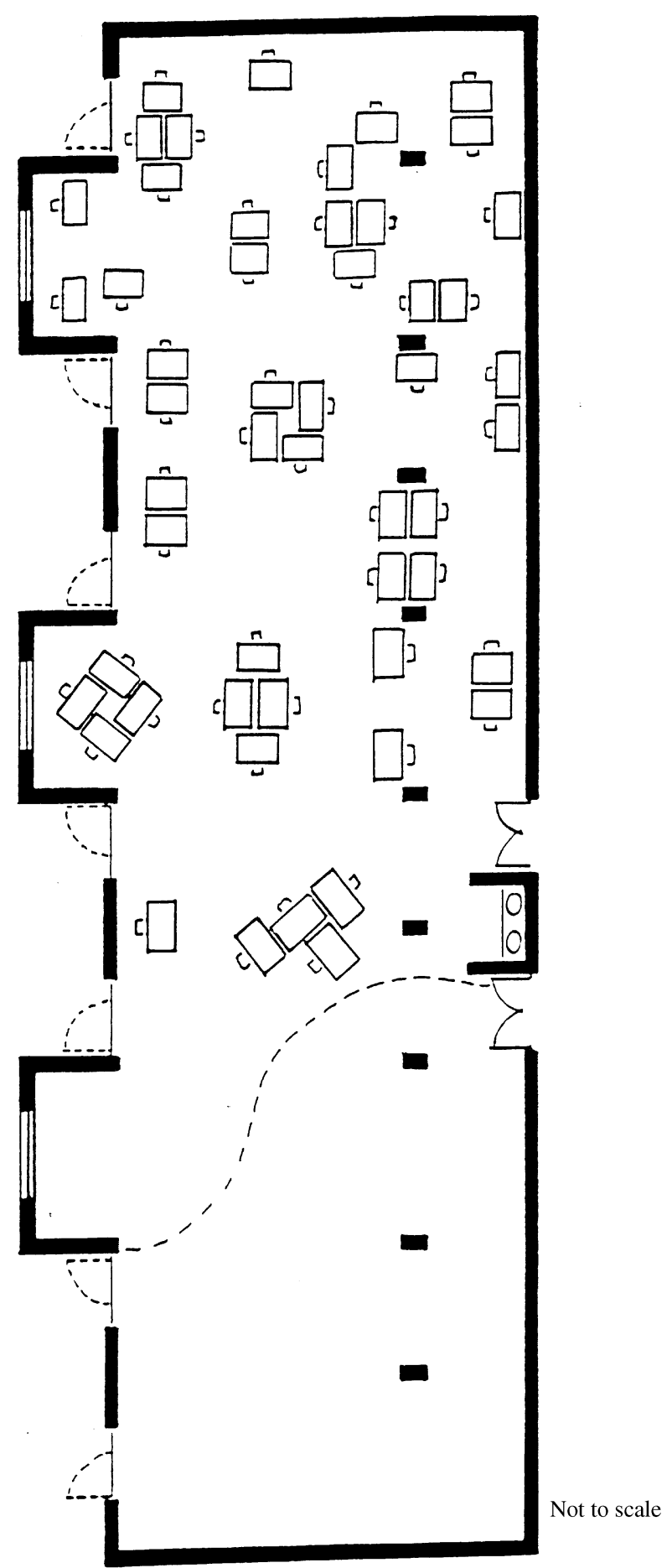

Figure 1. The studio plan.

\section{Participants}

There were 82 participants, of whom $44(54 \%)$ were male and $38(46 \%)$ were female. The age range was between 21 to 27 , and the mean age of the participants was 23.73. The majority of the participants 


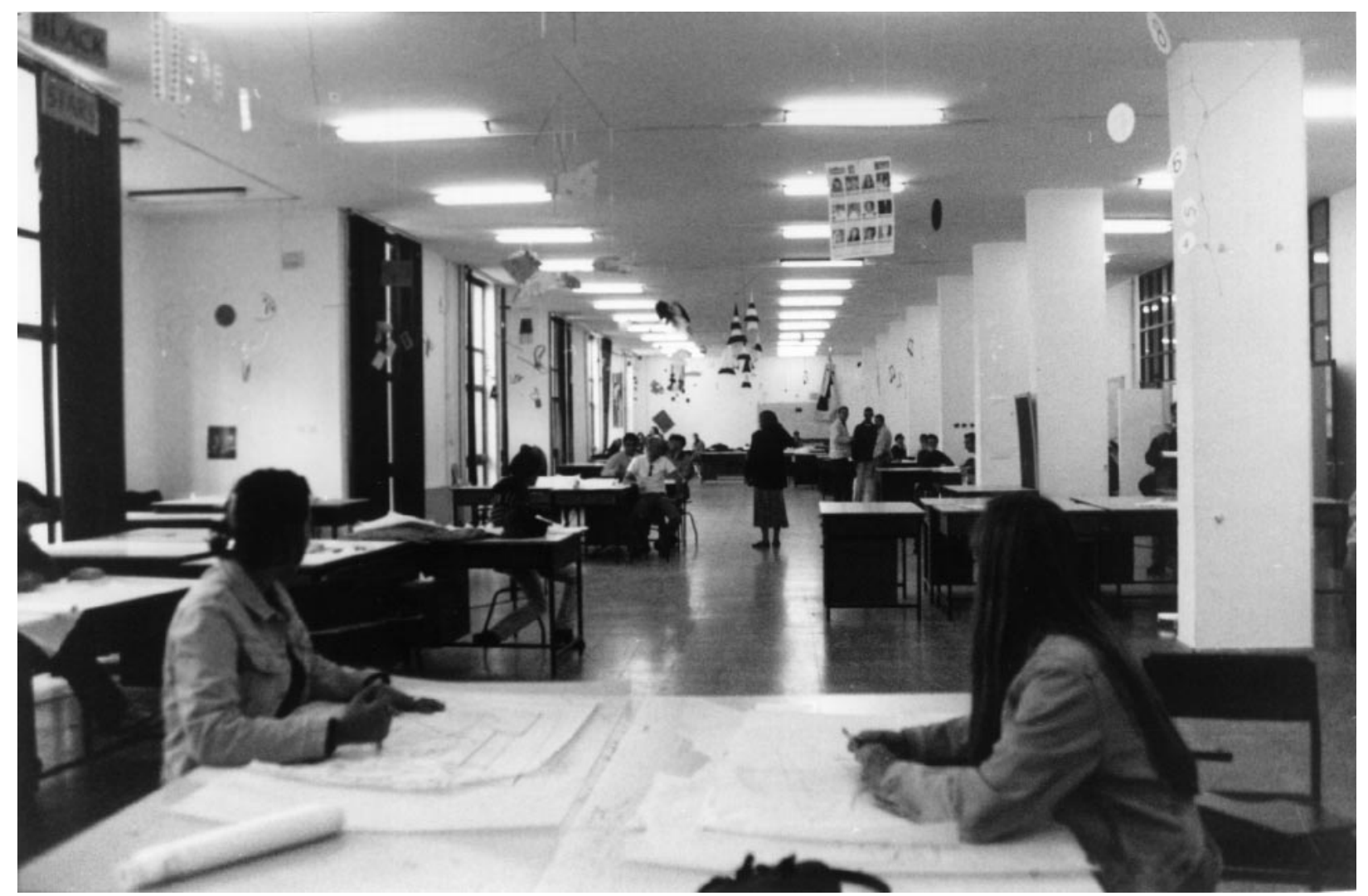

FigURE 2. View from the fourth year studio.

were living at home with their families (45\%), while 23 per cent of them were staying in student dormitories, and 22 per cent were living at home alone. The rest were housing with friends $(10 \%)$. Among the participants, 76 per cent had single bedrooms. Very few were sharing rooms with others.

\section{Results}

Related to social processes of environmental psychology

The first part of this study was aimed at finding out the way in which the participants' perceived the social processes of environmental psychology. The answers of the respondents' show that there were differences in the perception of privacy between individuals (see Appendix, Part I, Q. 4). Twenty-five per cent of the answers depended on the fact that privacy is a human right, 31.66 per cent directly related to the concept of one's freedom, and 23.34 per cent of the answers were closer to the privacy definitions found in the literature related to space use. The respondents $(20 \%)$ who gave answers in the classification of defensive attitudes stated that others should respect their privacy, otherwise they would have to take some precautions to avoid those who are disturbing their privacy (see Figure 3).

When respondents were asked what they do if they wished to be alone (see Appendix, Part I, Q. 5), the most common answer (approximately 41\%) was 'go to my desk' (see Figure 4). When arranging their tables (see Appendix, Part I, Q. 6), 61 per cent preferred grouping their tables with some good friends without considering the exact place in the studio, while others preferred to be near a wall side $(22 \%)$, near a window $(18.3 \%)$, or in a niche or between columns $(23 \cdot 2 \%)$. In order to increase the privacy level in the studio (see Appendix, Part I, Q. 7), the most popular answer (45\%) was to divide the existing space with partitions. Of the respondents, 30.5 per cent stated that the studio space should be smaller. Nearly 10 per cent of the students preferred to have working cabinets in which they can work either with a group of friends or alone within the studio space.

Thirty-five per cent of the students stated that they had put some personal belongings on and around their tables to define their territories, while 32 per cent use furniture or partitions when 
TABLE 1

Questions related to the six states of privacy

Solitude

I sometimes need to be alone.

I like to work in a big and crowded studio, since it prevents me from being alone.

I prefer working in a place, whether my house or dormitory, which is quiet and peaceful.

While I am working, I should be alone whether I am in my house or dormitory.

Being observed by others disturbs me.

Reserve

I avoid making a long conversation with someone I have just met.

I prefer being alone, instead of being in a crowd in the studio.

I like to keep a distance in personal relations with my friends in the studio.

I prefer as much as possible not to stay in a crowd.

Intimacy with family

I like to be with my family.

I do not like to be distrubed by others while I am doing an activity with my family.

I prefer living alone with my family away from others.

I like to share my problems only with my family.

While I am working, being with my family is more pleasant and makes me more productive.

Intimacy with friends

When I am unhappy and desperate, I like to have friends around me and I like them to make me happy.

In the studio, there are some special friends with whom I can share my secrets.

I like my friends in the studio to pay attention to me.

I am happy when others realize my success in the studio.

I like to meet new people.

Anonymity

I have to be encouraged to talk in front of a crowd in the studio, even when others do.

I like my design ideas to be known by others.

I like to be the centre of attention in the studio.

I prefer the audience to be strangers while I am presenting my project.

Isolation

I want to work alone in a space that belongs to me for the rest of my life.

I want some partitioned spaces to exist for private study in the studio.

I want to live alone in a place which is away from crowds.

I want a job which gives me the opportunity to work somewhere away from people and the city life.

defining their territory in the studio (see Appendix, Part I, Q. 8). Forty per cent of the participants considered their tables and surroundings as their personal space in the studio (see Appendix, Part I, Q. 9). Of the students, 35.5 per cent considered their houses and rooms as their personal spaces. Only four of the participants stated that they thought personal space was a circular area around the individual, which resembles the definition of personal space in literature (Gifford, 1987).
For better studying conditions, 35 per cent of the students stated that the studio should not be too crowded (see Appendix, Part I, Q. 10). Among the participants, 66 per cent felt crowded in the studio and these participants thought that the density of students was too high in the studio (see Appendix, Part I, Q. 11). Nearly half (51\%) of the participants preferred to keep a personal distance in their relationships with the other occupants (see Appendix, Part I, Q. 12). The general idea of the

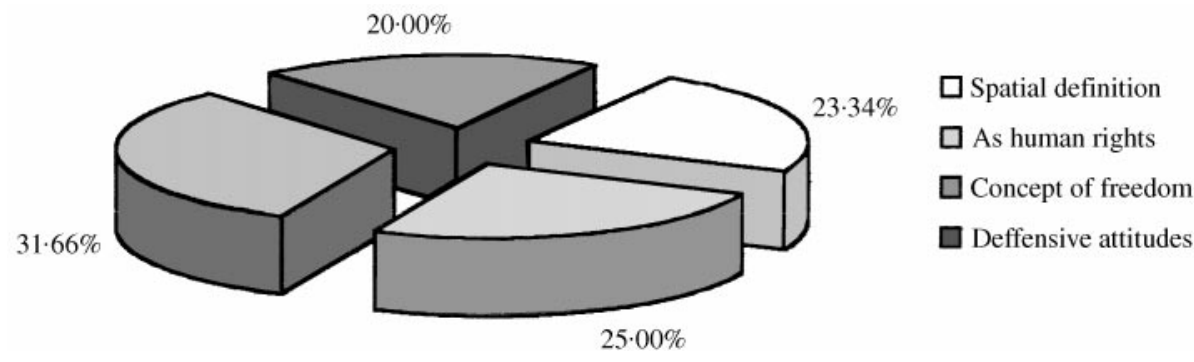

Figure 3. Percentages of the different perceptions about privacy. 


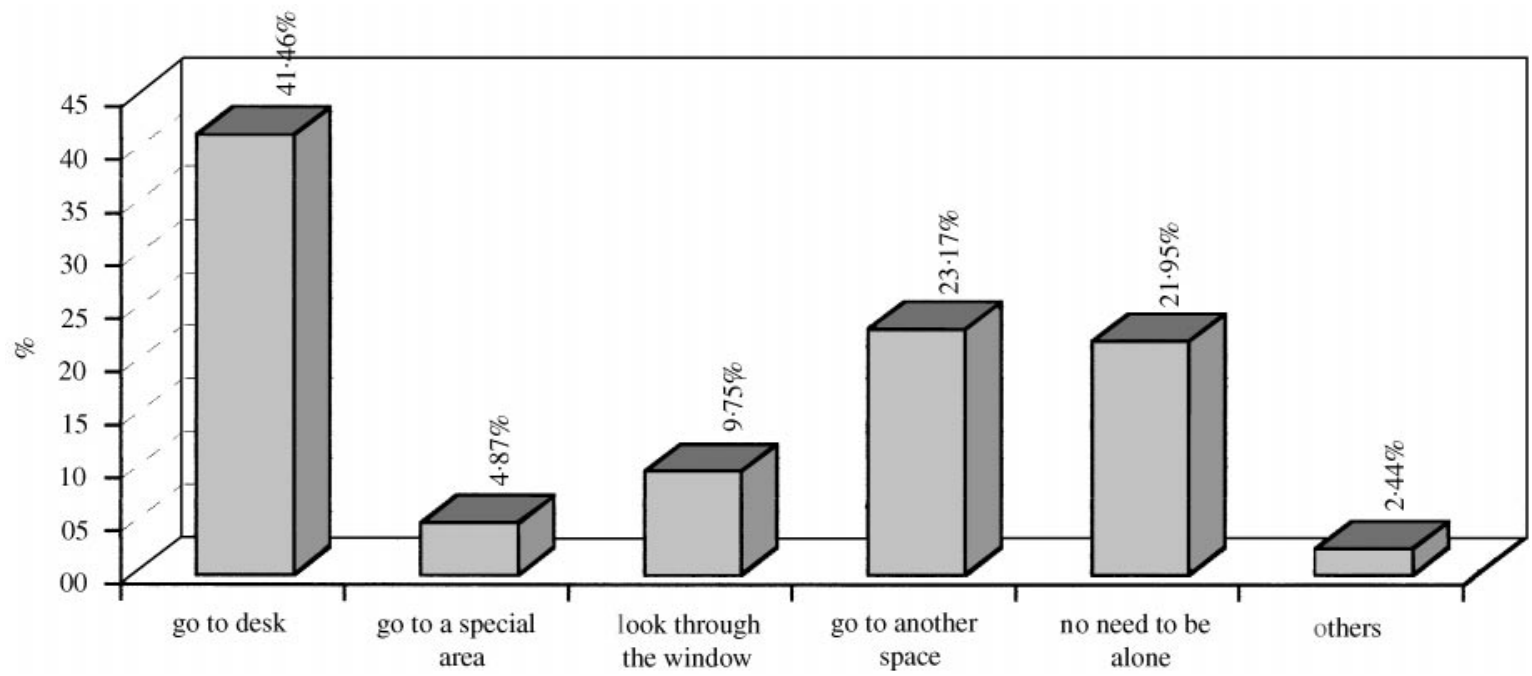

FiguRe 4. Measures for having privacy.

participants (see Appendix, Part I, Q. 13) was that there should be no more than 50 people in the studio (see Figure 5).

Nearly 60 per cent of the participants preferred to be alone at home or in the dormitory whilst designing, instead of being in the studio (see Appendix, Part I, Q. 14). Approximately 60 per cent of the participants shared their design ideas with the others in the studio, although most of them favour more isolation and secrecy in the studio (see Appendix, Part I, Q. 15).

It was aimed to investigate the methods used by the participants for preventing intrusions into their personal spaces (see Appendix, Part I, Q. 17). When the participants were asked to define their personal space and territory in the studio, they stated that they use personal belongings $(35 \%)$ and other physical objects around them (32\%) to specify their personal space and territory. Nearly 15 per cent of the respondents claimed that they do not do anything to prevent intrusions into their personal space, although most of these students were the ones whose perceptions of privacy were derived from defensive attitudes and/or human rights.

The design studio was assumed to be used all day long, but according to the results of this case study, it was obvious that it was used only during class hours. The main reason for this was that it did not have the required spatial characteristics. Consequently, it was perceived as a classroom in which lessons were conducted. Although it was assumed that the students should work in this space, they were trying to escape from the space as soon as possible. When the results of the research were considered, unfortunately, it became obvious that most of the students did not use the studio except during design hours, or only a few used this space very rarely in their free time (see Appendix, Part I, Q. 18-19). To understand the reasons behind this problem, besides the environmental characteristics of the studio, the preferences of the occupants should be identified.

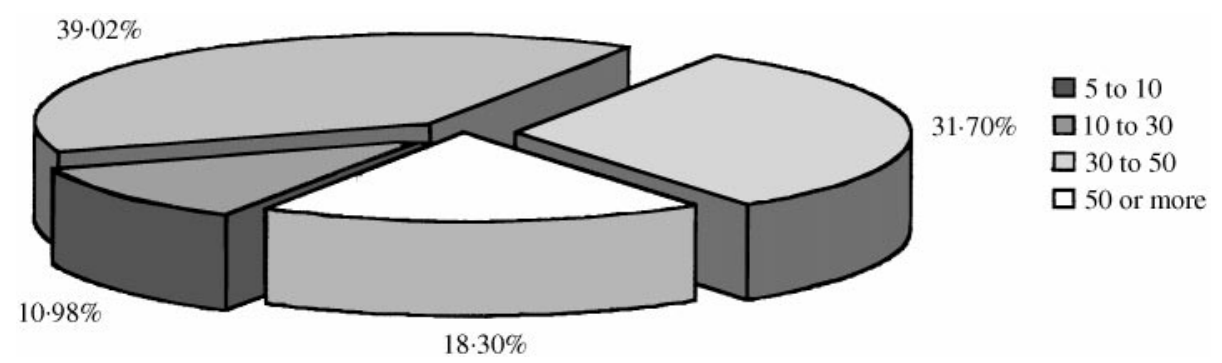

FiguRe 5. Number of students preferred in a studio. 


\section{Related to the states of privacy}

In the second part of the questionnaire, the six states of privacy defined by Pedersen (1979) were adapted to the studio environment. The privacy preferences of the participants were measured according to these specific conditions (see Appendix, Part II). One-way analysis of variance showed that the six states of privacy were significantly different from each other $(F=27.89$, df. $=5, p=0.000)$. A correlation among the six states of privacy was also calculated. Table 2 provides descriptive data of the correlation matrix between the six states of privacy. Solitude and reserve were slightly correlated (correlation coefficient $=0.52$ ), and intimacy with friends had a small negative relationship with solitude and reserve (correlation coefficient $=-0.09 ;-0.30$, respectively). The magnitude of this correlation would be expected to change somewhat with other sam- ples. From this correlation, it may be concluded that the states of privacy scores represent a high degree of independence from one another supporting the one-way analysis of variance results. Each state functions by itself, one kind of privacy does not need to go with another. For example, the preference of an individual can be for solitude, but this does not mean he/she also prefers isolation. Any of the six states, or more than one state can be unique to a particular person. One person could prefer any one state while one another person could prefer two or more states together.

The mean values and the standard deviations of both male and female respondents were found and the combined scores were calculated. The most preferred type of privacy was intimacy with friends (19.27), and the least preferred one was anonymity (9.27), as depicted in Table $3(p<0 \cdot 01)$. Females had a significantly higher mean for intimacy with

TABLe 2

Correlation among six states of privacy

\begin{tabular}{lrrrr}
\hline States of privacy & Solitude & Reserve & $\begin{array}{c}\text { Intimacy } \\
\text { with family }\end{array}$ & $\begin{array}{c}\text { Intimacy } \\
\text { with friends }\end{array}$ \\
\hline Reserve & 0.52 & & & \\
Intimacy with family & 0.40 & 0.40 & 0.12 & $0 \cdot 18$ \\
Intimacy with friends & -0.09 & -0.30 & 0.08 & -0.17 \\
Anonymity & -0.02 & 0.12 & $0 \cdot 17$ & $0 \cdot 27$ \\
Isolation & 0.43 & 0.50 & & \\
\hline
\end{tabular}

TABLE 3

Means and standard deviations according to sex and t-test values

\begin{tabular}{|c|c|c|c|c|c|}
\hline $\begin{array}{l}\text { States of } \\
\text { privacy }\end{array}$ & Sex & Number & Mean & $\begin{array}{l}\text { Standard } \\
\text { deviation }\end{array}$ & $t$-test \\
\hline \multirow[t]{3}{*}{ Solitude } & Male & 43 & $12 \cdot 81$ & $3 \cdot 37$ & 0.04 \\
\hline & Female & 37 & $12 \cdot 78$ & $3 \cdot 16$ & \\
\hline & Combined & 80 & $12 \cdot 80$ & $3 \cdot 26$ & \\
\hline \multirow[t]{3}{*}{ Reserve } & Male & 43 & $10 \cdot 35$ & 2.71 & $1 \cdot 16$ \\
\hline & Female & 38 & $9 \cdot 63$ & $2 \cdot 84$ & \\
\hline & Combined & 81 & $10 \cdot 01$ & $2 \cdot 78$ & \\
\hline \multirow[t]{3}{*}{ Intimacy with family } & Male & 41 & $12 \cdot 66$ & $3 \cdot 28$ & -2.92 \\
\hline & Female & 38 & 14.95 & $3 \cdot 69$ & \\
\hline & Combined & 79 & $13 \cdot 76$ & $3 \cdot 65$ & \\
\hline \multirow[t]{3}{*}{ Intimacy with friends } & Male & 43 & $18 \cdot 12$ & $4 \cdot 42$ & $-2 \cdot 86$ \\
\hline & Female & 38 & $20 \cdot 58$ & $3 \cdot 14$ & \\
\hline & Combined & 81 & $19 \cdot 27$ & 4.04 & \\
\hline \multirow[t]{3}{*}{ Anonymity } & Male & 43 & 9.63 & $2 \cdot 65$ & -0.95 \\
\hline & Female & 36 & $10 \cdot 17$ & $2 \cdot 31$ & \\
\hline & Combined & 79 & $9 \cdot 87$ & $2 \cdot 50$ & \\
\hline \multirow[t]{3}{*}{ Isolation } & Male & 43 & $12 \cdot 60$ & 3.70 & 1.98 \\
\hline & Female & 37 & $11 \cdot 14$ & $2 \cdot 80$ & \\
\hline & Combined & 80 & $11 \cdot 93$ & $3 \cdot 37$ & \\
\hline
\end{tabular}

The probability values are for $p<0 \cdot 01$, both two-tailed. 
friends and intimacy with family, but lower means for isolation and reserve $(p<0.01)$. The mean for solitude did not differ for the sexes $(p<0.01)$. A $t$-test was conducted by considering the scores of the two sexes. According to the scores of the $t$-test, it was obvious that there were differences in some privacy preferences between the two sexes. Table 3 provides descriptive information of the responses according to the mean values, standard deviations and $t$-test values. Although there was no difference between preferences of solitude, reserve, anonymity, and isolation among sexes; there was a significant difference among sexes in preferences of intimacy with family $(t=2.92, p=0.0046)$ and intimacy with friends $(t=2 \cdot 86, p=0.0055)$, with females preferring intimacy with family and males preferring intimacy with friends.

\section{Conclusion and discussion}

The three purposes of this study were (1) to identify the privacy regulations in the design studio; (2) to find the privacy needs or factors satisfied by the six types of privacy identified by Pedersen (1979); and (3) to compare the preferences of privacy factors of the different sexes.

The results of the research showed that, due to different individual characteristics, the definition of privacy differs for each individual. Similar situations are acceptable for the privacy preferences of the individuals while working in the studio. Nearly half of the students claimed that they preferred being at their tables when seeking privacy. Also, other individuals pointed out that they could not achieve privacy in the studio.

The factors which participants considered while arranging their tables were also important. Although more than 60 per cent of the participants claimed that they felt crowded and more than 30 per cent stated that they had to be alone in order to work, nearly 60 per cent preferred to locate their tables with a group of friends (see Figure 6). From this point, it is evident that although it seemed that most of the students stated that they preferred solitude or isolation, they preferred intimacy with friends in reality. For this reason, it can be said that the intrusions of others who were not intimate

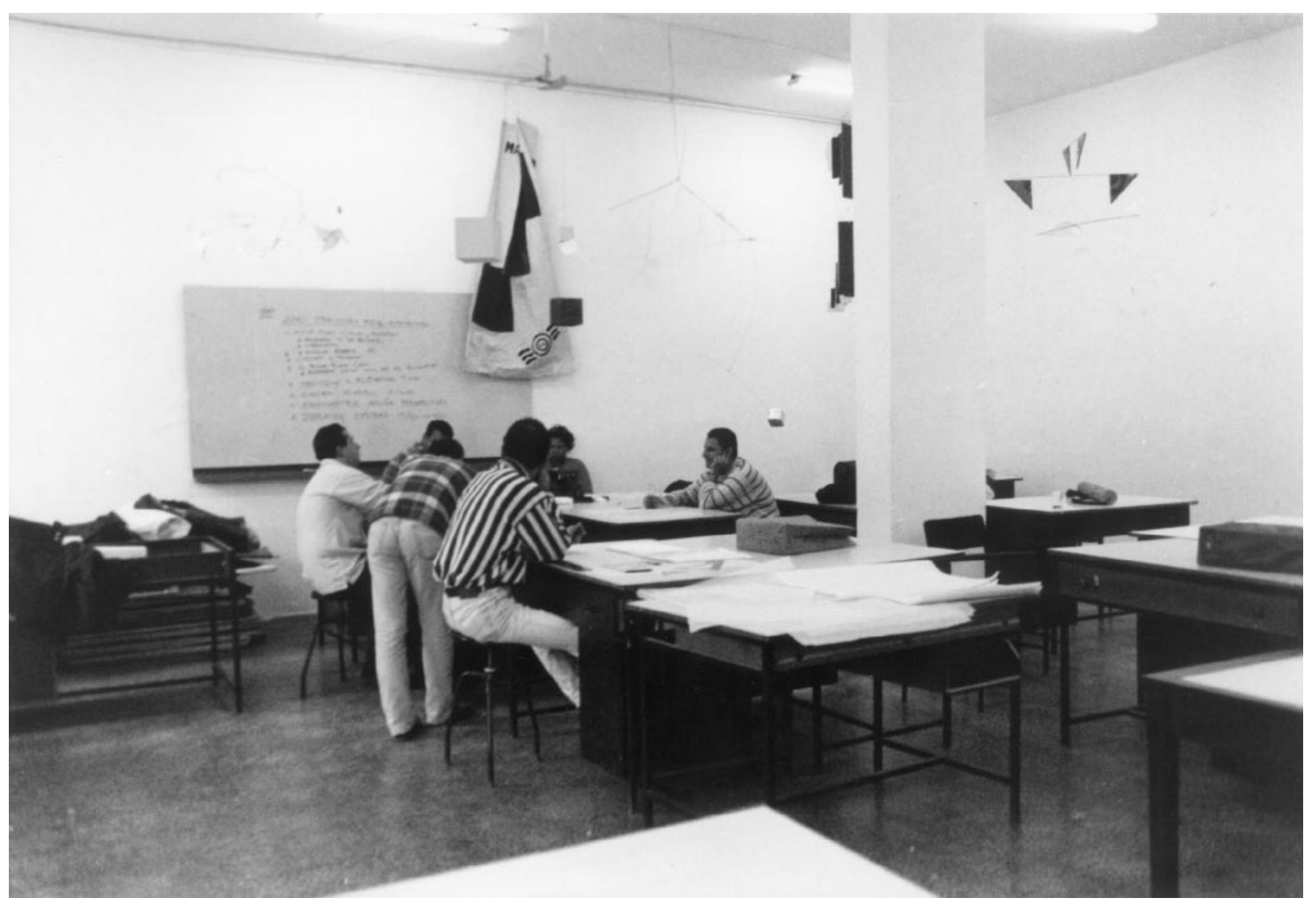

Figure 6. A group of students arrange their working tables together. 
with friends caused the feelings of over-crowding. The organization of the tables within the groups affects the satisfaction of the students. More effective use of space with some spatial precautions, such as using partitions to divide the huge volume of space, will affect the satisfaction level of the occupants. Providing a more controlled interaction level between the occupants could reduce the feeling of over-crowding.

Similarities and differences between the results of this research and others are noted. For example, the scores of Pedersen's research and this research differ. There are differences between the two studies in the preferences of reserve, but there is little difference in the preferences of the other states. The reason for this could be the difference in the cultural backgrounds of the participants in the two studies. Similar differences are present between Pedersen's (1979, 1982, 1987) and Rustemli and Kokdemir's (1993) studies. The outcome of this study is very similar to the outcome of Rustemli and Kokdemir's studies, since the participants are both from the same cultural background and age group.

Rustemli and Kokdemir's (1993) study was conducted among Turkish university students and not in a specified space. Results showed that intimacy with friends had the highest mean (17.64) and reserve had the lowest mean (11.92) (p. 809). This study, which is conducted in the design studio among Turkish students, showed that intimacy with friends had the highest mean (19.27), but anonymity had the lowest mean (9.87) as depicted in Table 3. Since both studies were conducted in the same non-Western culture, namely, the Turkish society, this study's findings support the previously conducted one in the intimacy with friends state. Due to the positive spatial characteristics of the design studio, reserve was not found to have the lowest mean in this study. The design students stated that they prevented intrusions into their personal space by locating their desks in a corner, between columns or in a niche. The reason for having anonymity as the lowest mean may be explained by the nature of the design course. The grade obtained at the end of a project is affected by the critiques obtained throughout the design process. Therefore, the design student may prefer to be remembered positively and distinguished from friends in order to guarantee a good grade.

In comparing the two studies related to the preferences of privacy factors of different sexes, both studies showed that females had significantly higher means for isolation and reserve than did males $(p<0.01)$. In addition, in this study females had a significantly higher mean for intimacy with family $(p<0.01)$.

Pedersen's analysis (1987, p. 1241), showed that the mean score for isolation was significantly higher for males (14.69) than for females (12.46) $(p \leq 0.05)$. On the other hand, the mean scores for females were significantly higher than for males on intimacy with family and intimacy with friends $(p \leq 0.05)$. No statistically significant difference was found between the means for the two sexes for reserve, solitude, and anonymity. This study also supported the notion that intimacy with family and intimacy with friends have to be considered separately. These findings verified that preference for a certain type of privacy depends not only on the situation but also on the cultural context.

Since the research was carried out through a specific case study, it is difficult to generalize the outcomes for all design education settings. For further studies, the same kind of research could be conducted in different design education institutions from different countries and the results evaluated in relation to each other for more general results. Beside the behavioural elements, there are also some other factors that cause dissatisfaction, such as technical factors like acoustics, lighting and thermal comfort considerations. Since the focal point of this paper was the concept of privacy within the design studio, other factors that caused dissatisfaction were not focused upon. Therefore, in further studies, these other factors can be analysed to evaluate the reasons for lack of privacy and dissatisfaction.

\section{Notes}

Reprint requests and correspondence should be addressed to: Dr O. Osman Demirbas, Department of Interior Architecture and Environmental Design, Bilkent University, 06533, Bilkent, Ankara, Turkey. E-mail: demirbas@bilkent. edu.tr

\section{References}

Ahretzen, S. \& Evans, G. W. (1984). Distraction privacy and classroom design. Environment and Behavior, 16, 437454.

Altman, I. (1975). The Environmental and Social Behavior. Monterey, CA: Brooks/Cole.

Altman, I. (1976). A conceptual analysis. Environment and Behavior, 8, 7-29.

Altman, I. (1977). Privacy regulation: Culturally universal or culturally specific. Journal of Social Issues, 33, 66-84. 
Canter, D. \& Canter, S. (1971). Close together in Tokyo. Design and Environment, 2, 61-63.

Chapin, F. S. (1951). Some housing factors related to mental hygiene. Journal of Social Issues, 7, 164-171.

Chermayeff, S. \& Alexander, N. Y. (1963). Community and Privacy: Toward a New Architecture of Humanism. New York: Doubleday.

Deasy, C. M. \& Laswell, T. E. (1985). Designing Places for People: A Handbook on Human Behaviour for Architects, Designers and Facility Managers. New York: Broadway.

Demirbas, Ö. O. (1997). Design studio as a life space in architectural education: Privacy requirements. Master Thesis. Ankara: Bilkent.

Demirkan, H. (1996). Design criteria for better learning environment. In: A. Ö. Özok \& G. Salvendy, (Eds), Proceedings of the $1^{\text {st }}$ International Conference on Applied Ergonomics. Istanbul, pp. 357-360.

Duvall-Early, K. \& Benedict, J. D. (1992). The relationships between privacy and different components of job satisfaction. Environment and Behaviour, 24, 670-679.

Galvin, M. (1993). The colombine school: A principle reflects on the influence of school design. Children's Environment, 10, 99-112.

Gavison, R. (1984). Privacy and the limits of law. In F. D. Shoeman, (Ed.), Philosophical Dimensions of Privacy: An Anthology. Cambridge: Cambridge University Press, pp. 346-402.

Gifford, R. (1987). Environmental Psychology: Principles and Practice. Allyn and Dacon: Massachusetts.

Hall, T. (1969). The Hidden Dimension. New York: Doubleday Co.

Kupritz, V. W. (1998). Privacy in the workplace: The impact of building design. Journal of Environmental Psychology, 18, 341-356.

Marshall, N. J. (1974). Dimensions of privacy preferences. Multivariate Behavioral Research, 9, 255-272.

Nelson, D. \& Sundt, J. (1993). Changing the architecture of teachers' minds. Children's Environment, 10, 159-169.

Newell, P. B. (1994). A system model of privacy. Journal of Environmental Psychology, 14, 65-78.

Newell, P. B. (1995). Perspectives on privacy. Journal of Environmental Psychology, 15, 87-104.

Newell, P. B. (1998). A cross-cultural comparison of privacy definitions and functions: A system approach. Journal of Environmental Psychology, 18, 357-371.

Pedersen, D. M. (1979). Dimensions of privacy. Perceptual and Motor Skills, May, 1291-1297.

Pedersen, D. M. (1982). Personality correlates of privacy. Journal of Psychology, 112, 11-14.

Pedersen, D. M. (1987). Sex differences in privacy preferences. Perceptual and Motor Skills, 64, 1239-1242.

Pedersen, D. M. (1997). Psychological functions of privacy. Journal of Environmental Psychology, 17, 147-156.

Rustemli, A. \& Kokdemir, D. (1993). Privacy dimensions and preferences among Turkish students. The Journal of Social Psychology, 133, 807-814.

Sanoff, H. (1993). Designing a responsive school environment. Children's Environment, 10, 140-153.

Schoemen, F. D. (1984). Privacy: Philosophical dimensions of the literature. In F. D. Schoeman, (Ed.), Philosophical Dimensions of Privacy: An Anthology. Cambridge: Cambridge University Press, pp. 1-33.
Schön, D. A. (1984). The architectural studio as an exemplar of education for reflection-in-action. Journal of Architectural Education, 38, 2-9.

Schön, D. A. (1987). Educating the Reflective Practitioner. San Fransisco: Jossey-Bass Publishers.

Shaffer, D. W. (no date). Understanding design learning. The design studio as a model for education. Available: http://www.media.mit.edu/people/dws/papers/design studio/index.html [February 26 1999].

Stamps, A. E. (1994). Jungian epistemological balance: A framework for conceptualizing architectural education. Journal of Architectural Education, 48, 105-112.

Taylor, A. (1993). The learning environment as a three dimensional textbook. Children's Environment, 10, 170-179.

Weiss, P. (1983). Privacy. Carbondale, IL: Southem Illinois University Press.

Westin, A. F. (1967). Privacy and Freedom. New York: Atheneum.

\section{Appendix}

\section{Questionnaire}

Part I. This section contains some questions, which are aimed to measure the concepts of privacy, crowding territoriality, and personal space, within a design studio. More than one answer can be given to each question if necessary.

(1) Age...... Sex....F $\square$.....M $\square \quad$ Studio No........

(2) Where do you live? (a) In a dormitory (b) At home with family (c) At home alone (d) At home with friends (e) Other

(3) With how many people do you share your bedroom or dormitory room with?

(a) Single (b) Two people (c) Three people (d) Four people (e) Other

(4) What does privacy mean, to you? Please answer briefly.

(5) What do you do to be alone during class hours? (a) I go to my desk (b) I go to a special corner or an area in the studio (c) I look through the window (d) I leave the studio and go to another space (e) I do not need to be alone (f) Other....

(6) Which factors did you consider while locating your desk in the studio?

(a) To be near a wall (b) To be near a window

(c) To be in or between the physical elements of the space such as columns or niches, if there are any (d) To group the desks with some of the close friends (e) Other (f) None.

(7) What should be done in order to increase the privacy level in the studio?

(a) There should be study cabinets for single study (b) There should be study cabinets for group study (c) There should be partitions in the space (d) The studio should be smaller (d) Other

(8) What should you do in order to classify your territory in the studio?

(a) I will put some personal objects such as 
posters, flowers etc. on the wall behind, or in front of the desk (b) I will specify my territory by some spatial elements as furniture or panels (c) Other (d) None.

(9) Where do you consider as your personal space?

(10) Under what conditions do you study more comfortably?

(a) Crowded and noisy (b) Crowded and quite (c) Should not be too much crowded (d) I am not able to study in the design studio under any condition (e) Other

(11) Is your studio crowded? If you think it is crowded, explain the reasons of it by considering the characteristics of the space.

(12) What should be the minimum distance between the others and you in the studio (Please indicate in $\mathrm{cm}$ ).

(13) What should be the maximum population of the studio that you are using?

(a) 5-10 (b) 10-30 (c) 30-50 (d) 50 or more.
(14) I prefer. while designing. (a) Being alone at home or dormitory (b) Being with family at home (c) Being with friends at the dormitory (d) Being alone at the studio (e) Being with friends at the studio (f) Other

(15) I ...............share my design ideas with other students in the studio. (a) Always (b) Sometimes (c) Rarely (d) Never.

(16) In the design studio, I know (a) Everybody (b) Most of the people (c) Only a few people who are close friends (d) No one.

(17) What should be done to prevent intrusions to your personal space?

(18) How often do you use the studio except the class hours?

(a) Once or twice a day (b) Once or twice a week (c) Once a week (d) Rarely (e) None.

(19) Explain briefly the reason of being in the studio out of the class hours?

Part II. In this section, decide how valid each statement for you and mark the appropriate number between the interval 1 to 5 .

(1) I sometimes need to be alone.

(2) I avoid making a long conversation with someone I have just met.

(3) I like to be with my family.

(4) When I am unhappy and desperate, I like to have friends around me and I like them to make me happy.

(5) I have to be encouraged to talk in front of a crowd in the studio, even when others do.

(6) I like my design ideas to be known by others.

(7) I want to work alone in a space that belongs to me for the rest of my life.

(8) I like to be the centre of attention in the studio.

(9) I like to work in a big and crowded studio, since it prevents you from being alone.

(10) I do not like to be disturbed by others while I am doing an activity with my family.

(11) I want some partitioned spaces to exist for private study in the studio.

(12) I prefer working in a place, whether my house or dormitory, which is quiet and peaceful.

(13) While I am working. I should be alone whether I am in my house or dormitory.

(14) In the studio, there are some special friends with whom I can share my secrets.

(15) I prefer the audience to be strangers while I am presenting my project.

(16) I prefer being alone, instead of being in crowd in the studio.

(17) I prefer living alone with my family away from others.

(18) I like my friends in the studio to pay attention to me.

(19) I am happy when others realize my success.

(20) I want to live alone in a place which is away from the crowd.

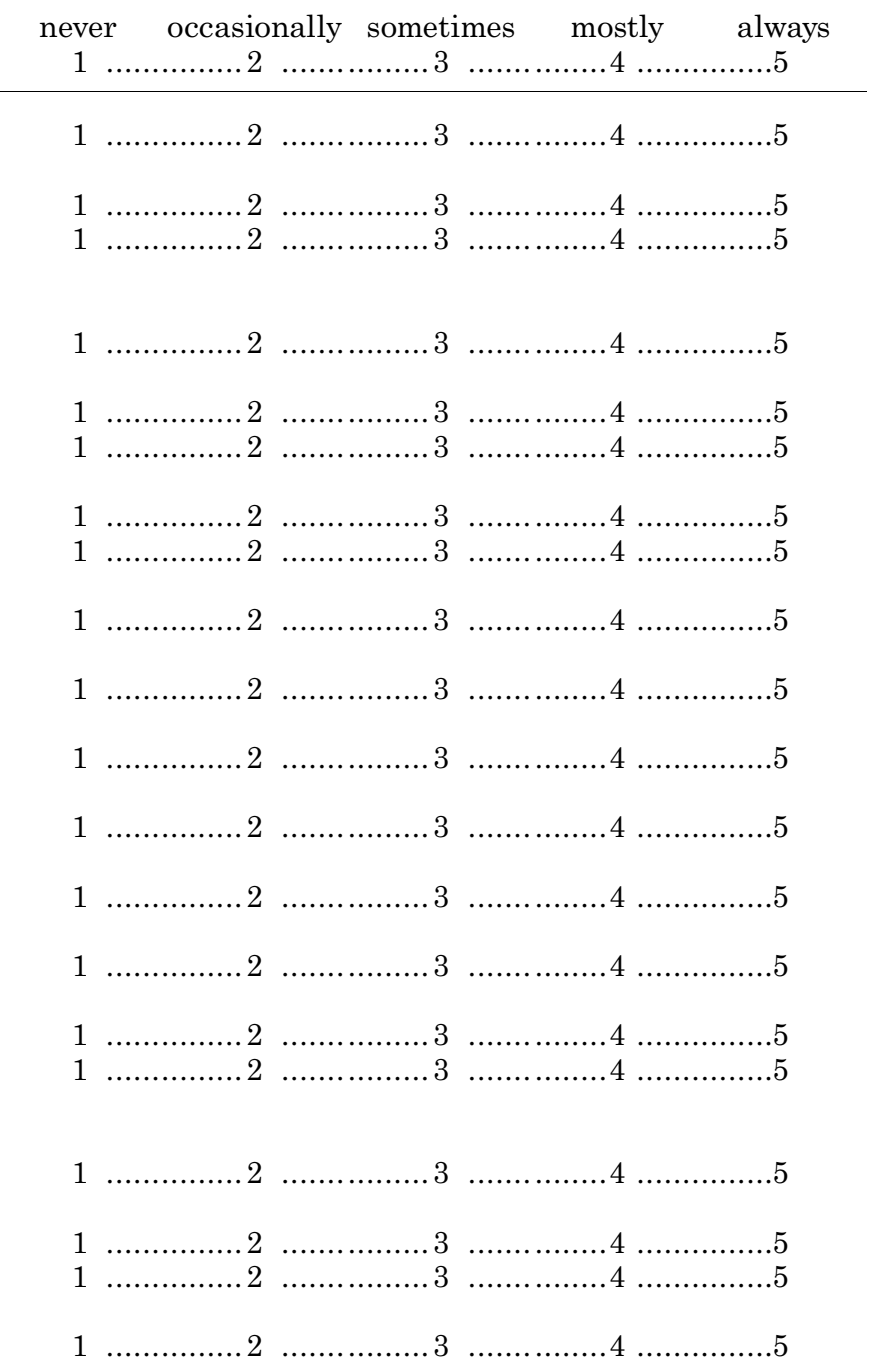


(21) Being observed by others disturbs me.

(22) I like to share my problems only with my family.

(23) I like to keep a distance in personal relations with my friends in the studio.

(24) I want a job which gives me the opportunity to work somewhere away from people and the city life.

(25) While I am working, being with my family is more pleasant and makes me more productive.

(26) I like to meet new people.

(27) I prefer as much as possible not to stay in a crowd.

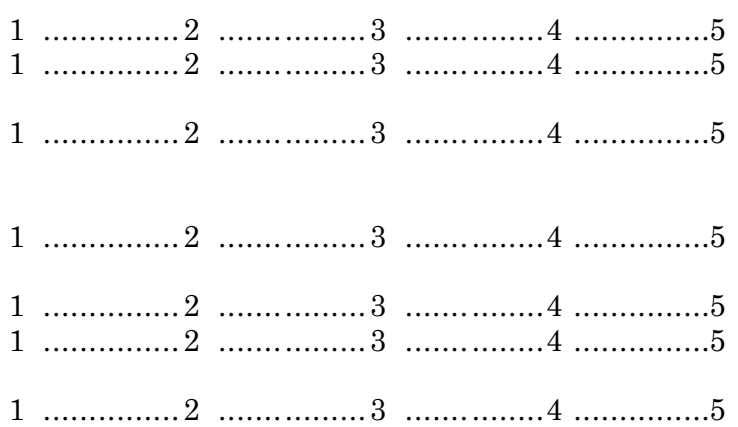

